\title{
Study of Decomposition of Thermoelastic and Non-thermoelastic Martensite in $\mathrm{Cu}$-Zn-Al Alloys
}

\author{
M. Vojtko a and S. Longauer \\ Department of Material Science, Technical University of Košice, Slovakia
}

\begin{abstract}
Cu}$ based alloys are considerable traditional material with good shape memory effect. Reversal thermoelastic transformation from parent phase to martensite is necessary requirement for taking place of shape memory effect. The significant phase for taking place shape memory effect in $\mathrm{CuZnAl}$ alloy is ordered $\beta$ phase with ideal ratio of valence electrons to atom $e / a=1.48$. The alloys with ratio e/a lesser than 1.42 after quenching from single phase beta region undergo non-thermoelastic martensitic transformation and thereby don't possess shape memory effect. This can be obtained by quenching from dual phase $\alpha+\beta$ region in some alloys. The paper deals with comparison of decomposition at elevated temperatures of thermoelastic and non-thermoelastic martensite to more stable products. Influence of stabilization of martensite on decomposition at elevated temperatures is also studied. Depending up initial state of material and condition of decomposition it could be possible to obtain structure containing $\alpha$ and $\beta$ or $\gamma$ phase with miscellaneous morphology and it could be possible to used for modification of definitive structure or for modification of structure before another heat treatment. Study of differences between thermoelastic and non-thermoelastic martensities would be useful for intensification of shape memory properties of $\mathrm{Cu}$ based alloys.
\end{abstract}

\section{Introduction}

Thermoelastic transformation is basic condition for exibition of shape memory effect. In CuZnAl shape memory alloys, $\beta$ phase is responsible for shape memory effect, and the best ratio of valence electrons to atom is 1.48 . If this ratio is decreasing approximately under 1.42 , shape memory effect disappears. $\mathrm{CuZnAl}$ shape memory alloys with low valence electron to atom ratio don't show any shape memory effect and thus martensite in that alloys is non-thermoelastic.

It is difficult to distinguish thermoelastic and non-thermoelastic martensite by clasic light microscopy. One of the possibilitties how to distinguish these two types of martensite is annealing at elevated temperatures. At elevated temperatures samples can undergo various transformations, and thus it can be assumed, that there are different types of transformation for different types of martensites. Fixing the state at elevated temperate it would be possible to observe state of structure at elevated temperature and thus to estimate processes taked place during heating and holding at this temperature.

$\mathrm{CuZnAl}$ alloys are specially sensible to stabilisation of martensite effect and this effect degrades shape memory properties. The main cause of stabilisation is presence of vacancy which can block interfaces and such stabilised martensite has similar properties like non-thermoelastic martensite.

\footnotetext{
a e-mail: marek.vojtko@tuke.sk
} 
Table 1. Chemical composition of experimental materials (weight \%).

\begin{tabular}{lllll}
\hline & $\mathrm{Cu}$ & $\mathrm{Zn}$ & $\mathrm{Al}$ & $\mathrm{e} / \mathrm{a}$ \\
\hline $\mathrm{B}$ & 73.99 & 21.39 & 4.62 & 1.4026 \\
$\mathrm{~T} 1$ & 68.26 & 27.55 & 4.1 & 1.4434 \\
\hline
\end{tabular}

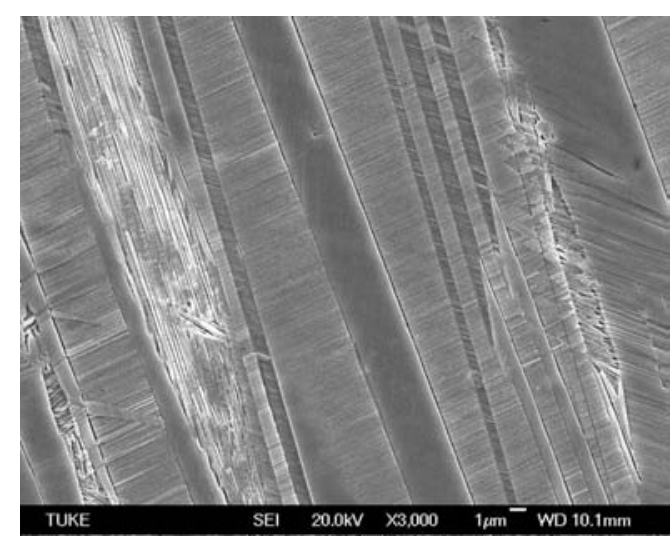

Fig. 1. Structure of alloy B quenched from $850^{\circ} \mathrm{C}$ and annealed at $300^{\circ} \mathrm{C}$.

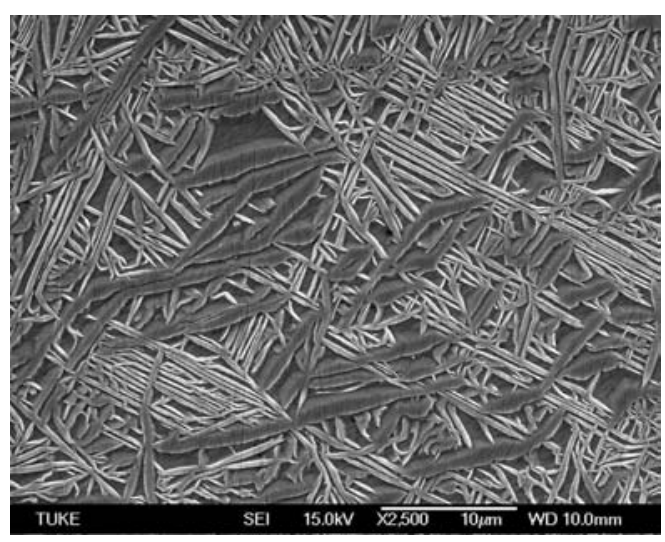

Fig. 2. Structure of alloy $\mathrm{T} 1$ quenched from $850{ }^{\circ} \mathrm{C}$ and annealed at $300^{\circ} \mathrm{C}$.

\section{Experimental}

There was used two different alloys with chemical composition given in table 1. Chemical composition was determined by EDX analysis and valence electrons to atom ratio was calculated.

The alloy B doesn't account any shape memory properties after quenching from single phase $\beta$ region but that one accounts significant shape memory effect after quenching from dual phase $\alpha+\beta$ region. On the other hand alloy T1 accounts good shape memory properties after quenching from single phase $\beta$ region with transformation temperatures close to ambient temperature.

Samples from B alloy was quenched from temperature range $630^{\circ} \mathrm{C}$ to $850^{\circ} \mathrm{C}$ to water with room temperature. Some of them was immediately after quenching annealed at $170^{\circ} \mathrm{C}$, with holding time 10 minutes and quenched to water with room temperature. Sample from T1 alloy was quenched from $850^{\circ} \mathrm{C}$ to room temperature water also. There was no annealing at $170^{\circ} \mathrm{C}$ in T1 alloy sample.

Some of samples was in next step annealed at elevated temperatures, mainly at $300^{\circ} \mathrm{C}$ with holding time 30 minutes and quenched to room temperature water. The aim of this heat treatment was decomposition of metastable phases like martensite and low temperature parent phase to more stable products.

\section{Results and discussion}

Figure 1 shows structure of alloy B quenched from $850^{\circ} \mathrm{C}$ (single phase $\beta$ region) and annealed at $300^{\circ} \mathrm{C}$. On the other hand, figure 2 shows structure of alloy T1 after the same heat treatment like previous one.

Alloy T1, with higher valence electrons to atom ratio $(e / a=1.4434)$, at room temperature consists of low temperature parent phase with small volume fraction of martensite after quenching from $850^{\circ} \mathrm{C}$. During the heating to $300^{\circ} \mathrm{C}$ all of martensite transforms to parent phase and in next step parent phase transforms to bainite, as it can be seen on figure 2 .

Alloy $\mathrm{B}$, with lower valence electrons to atom ratio $(e / a=1.4026)$, after quenching from $850{ }^{\circ} \mathrm{C}$ consists of non-thermoelastic martensite, and thus in the process of heating to $300^{\circ} \mathrm{C}$ 


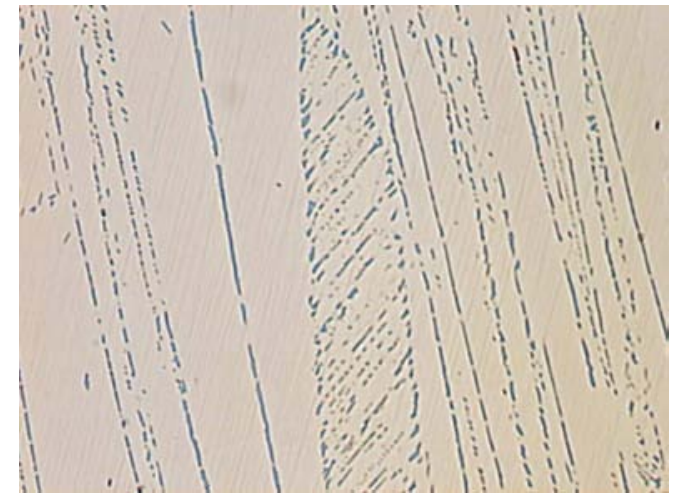

Fig. 3. Structure of alloy B quenched from $850^{\circ} \mathrm{C}$ and annealed at $400{ }^{\circ} \mathrm{C}$, holding time 24 hours, 1000x.

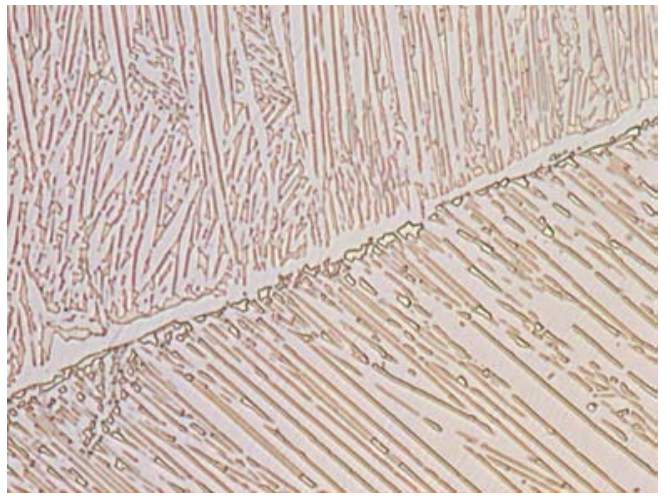

Fig. 4. Structure of alloy B quenched from $850^{\circ} \mathrm{C}$ and annealed at $600^{\circ} \mathrm{C}$, holding time 60 seconds, 1000x.

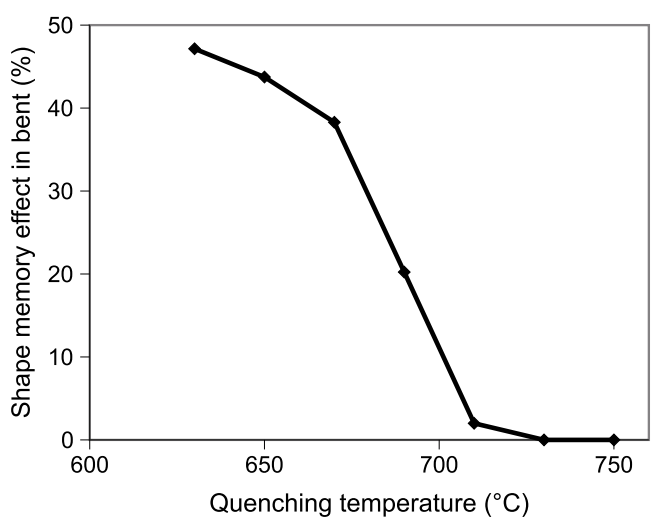

Fig. 5. Shape memory effect in bending as function of quenching temperature.

there is no transformation to parent phase. In this case, martensite directly transforms to more stable products with martensite like morphology. Martensite decomposes to $\alpha+\gamma$ phases at lower temperatures (figure 3) and to $\alpha+\beta$ phases at higher temperatures (figure 4 ). $\beta$ and $\gamma$ phases precipitate on martensite plate boundaries and stacking faults.

In alloy B is also possible to obtain thermoelastic martensite by quenching from dual phase $\alpha+\beta$ region. Some measurements was presented in another work [1]. Autors measured amount of shape memory effect in bending and showed that significant shape memory effect can be obtained by quenching from dual phase region $\alpha+\beta$ and upquenching at $170^{\circ} \mathrm{C}$ during 10 minutes and that shape memory efect is decreasing with increasing quenching temperature (figure 5).

It can be shown by annealing at $300^{\circ} \mathrm{C}$ with holding time 30 minutes that in that samples exists thermoelastic and non-thermoelastic martensite, that is, in samples are mobile and blocked (immobile) interfaces simultaneously. It can be assumed, that amount of shape memory effect depends on amount of thermoelastic martensite. Structures of samples of alloy B quenched from dual phase $\alpha+\beta$ region, upquenched and annealed (decomposed) at $300{ }^{\circ} \mathrm{C}$ are presented on figures $6,7,8,9,10,11$ and 12 .

The factors influenced on amount of shape memory effect in alloy B were described early [2]. Authors explained influence of degree of order, stacking fault energy and volume fraction of $\alpha$ phase on one way and two way shape memory effect.

On the basis of observed structures of alloy B decomposed at elevated temperatures a model of loss of shape memory effect with increasing quenching temperature can be suggested. 


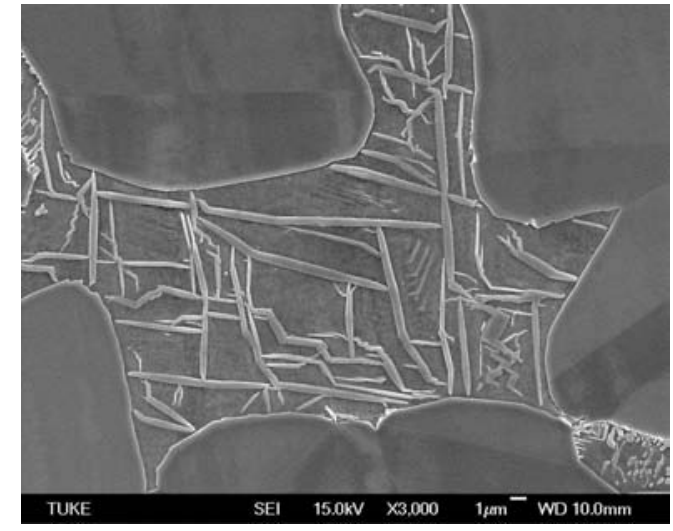

Fig. 6. Structure of alloy B quenched from $630^{\circ} \mathrm{C}$, upquenched at $170{ }^{\circ} \mathrm{C}$ and annealed at $300^{\circ} \mathrm{C}$.

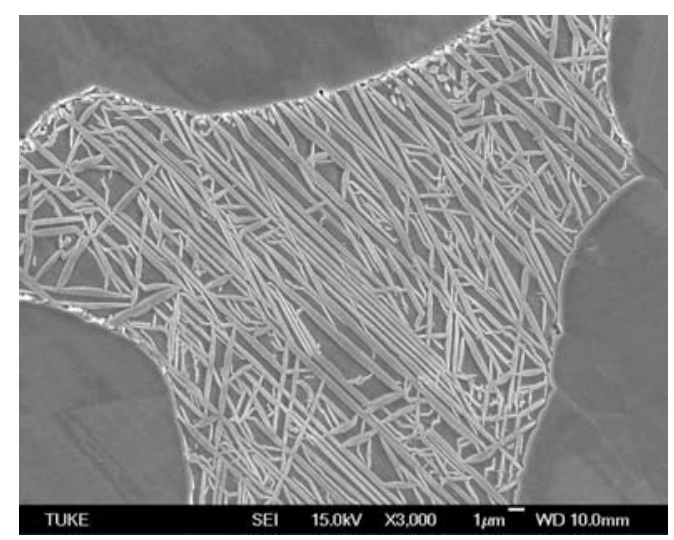

Fig. 8. Structure of alloy B quenched from $670^{\circ} \mathrm{C}$, upquenched at $170^{\circ} \mathrm{C}$ and annealed at $300^{\circ} \mathrm{C}$.

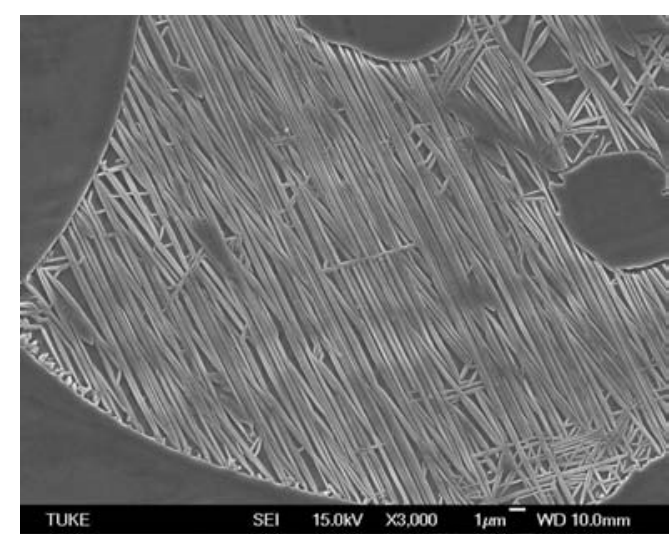

Fig. 10. Structure of alloy $B$ quenched from $710^{\circ} \mathrm{C}$, upquenched at $170^{\circ} \mathrm{C}$ and annealed at $300^{\circ} \mathrm{C}$.

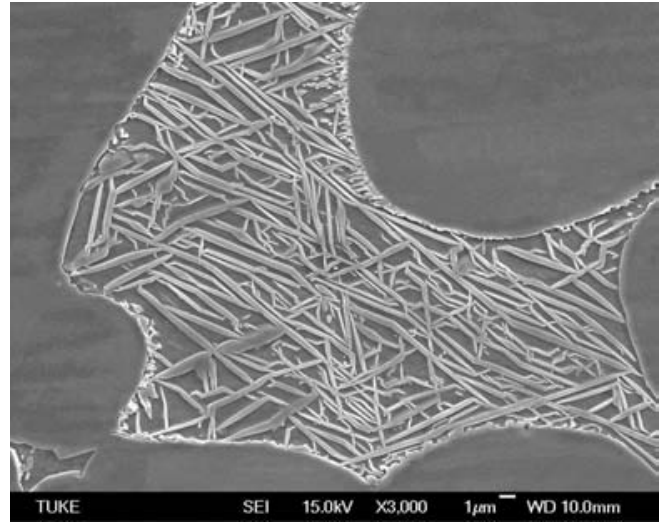

Fig. 7. Structure of alloy B quenched from $650^{\circ} \mathrm{C}$, upquenched at $170^{\circ} \mathrm{C}$ and annealed at $300^{\circ} \mathrm{C}$.

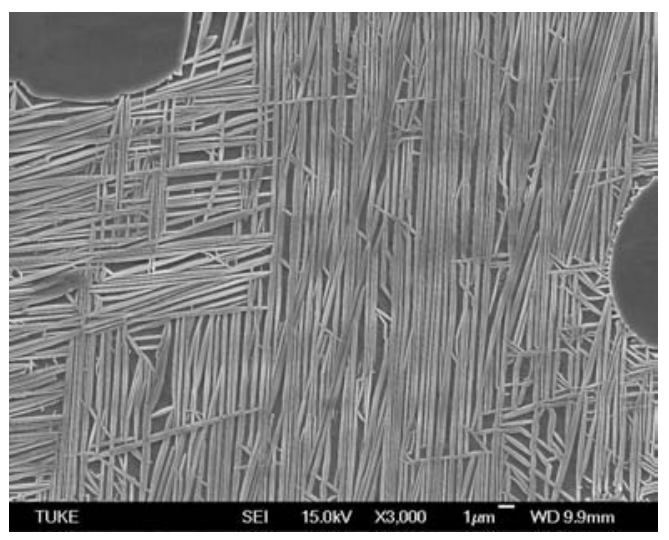

Fig. 9. Structure of alloy B quenched from $690^{\circ} \mathrm{C}$, upquenched at $170^{\circ} \mathrm{C}$ and annealed at $300^{\circ} \mathrm{C}$.

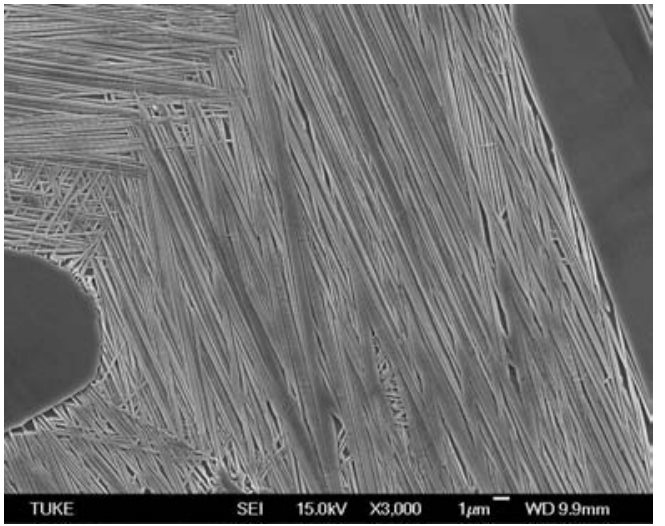

Fig. 11. Structure of alloy $B$ quenched from $730^{\circ} \mathrm{C}$, upquenched at $170^{\circ} \mathrm{C}$ and annealed at $300^{\circ} \mathrm{C}$. 


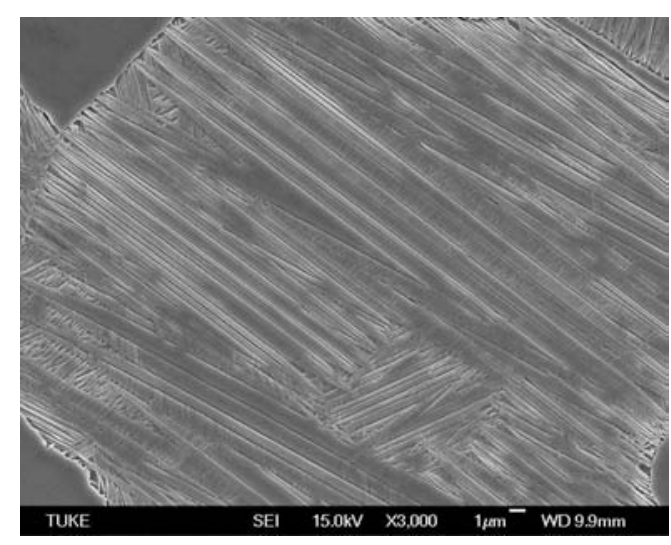

Fig. 12. Structure of alloy $B$ quenched from $750{ }^{\circ} \mathrm{C}$, upquenched at $170^{\circ} \mathrm{C}$ and annealed at $300^{\circ} \mathrm{C}$.

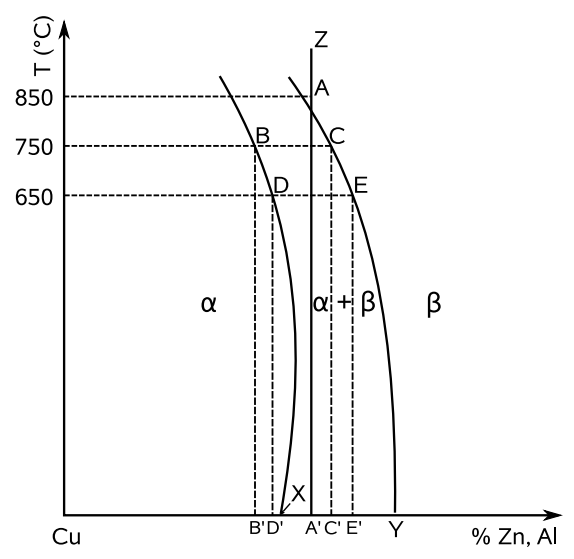

Fig. 13. Simplified model of quasi-binary diagram $\mathrm{Cu}-\mathrm{Zn}, \mathrm{Al}$.

A simplified quasi-binary diagram can be drawn (figure 13) and some pre-requisites can be assumed:

- driving force of martensitic transformation from parent phase is commensurable to difference of chemical composition of equilibrium state of $\beta$ phase and state at actual temperature. This difference can be expressed from figure 13 as distance of lines CC' and CY for quenching temperature $750^{\circ} \mathrm{C}$ and EE' and EY for quenching temperature $650^{\circ} \mathrm{C}$

- stacking fault energy decreases with increasing quenching temperature [2]

- and volume fraction of martensite during the martensitic transformation in shape memory alloys is function of actual temperature of transformation

From this assumptions is obvious, that sample quenched from higher temperature from dual phase region reaches adequate difference in chemical composition earlier, that is at higher temperature than sample quenched from lower temperature, and thus the temperature of starting of martensitic transformation is higher. Equilibrium of stacking fault energy and energy needed for twinning shifts towards lower temperatures with raising quenching temperature. It can be concluded that martensite which forms at quenching from higher temperatures has more interfaces with higher density of dislocations, and thus these interfaces are blocked and immobile. Martensite which forms at quenching from lower temperatures has coherent interfaces with existing parent phase and thus these interfaces are able of the motion. From this can be concluded, that volume fraction of mobile and immobile interfaces is dependent on quenching temperature, and thus samples quenched from different temperature from dual phase $\alpha+\beta$ region show variable volume fraction of thermoelastic and non-thermoelastic martensite. Finally, volume fraction of thermoelastic martensite is responsible for amount of shape memory effct.

Stabilisation of martensite has significant influence on shape memory effect and it was in detail described in work [3]. Figure 14 shows alloy B quenched from $650^{\circ} \mathrm{C}$, upquenched at $170^{\circ} \mathrm{C}$ and finally decomposed at $300^{\circ} \mathrm{C}$. On the next figure is presented alloy B quenched from $650^{\circ} \mathrm{C}$ and decomposed at $300^{\circ} \mathrm{C}$, that is without upquenching. It can be seen various volume fraction of mobile and immobile interfaces, and thus structure of decomposed stabilised martensite has similar features like a structure of decomposed non-thermoelastic martensite.

From that can be concluded, that stabilisation of martensite in alloy B has similar influence on shape memory effect like increasing of quenching temperature. Probably vacancies are the most important factor of stabilisation of martensite, and thus can be assumed, that vacancies are responsible for blocking of motion of interfaces. 


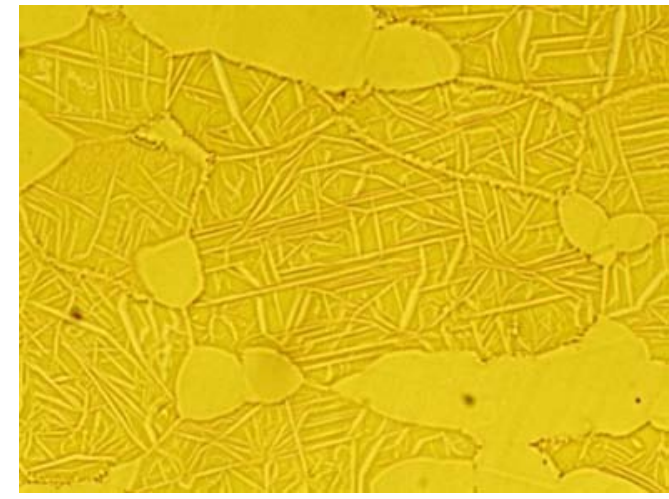

Fig. 14. Structure of alloy $B$ quenched from $650^{\circ} \mathrm{C}$, upquenched at $170^{\circ} \mathrm{C}$ and annealed at $300^{\circ} \mathrm{C}, 1000 \mathrm{x}$.

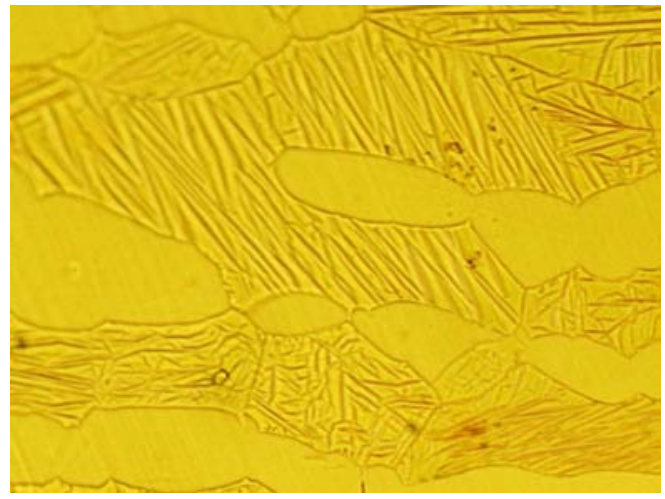

Fig. 15. Structure of alloy $B$ quenched from $650^{\circ} \mathrm{C}$ and annealed at $300^{\circ} \mathrm{C}, 1000 \mathrm{x}$.

\section{Conclusions}

Diferences during the decomposition of thermoelastic and non-thermoelastic martensite in $\mathrm{CuZnAl}$ alloys by decomposition annealing was presented.

On the basis of observed structures of samples subjected to decomposition annealing can be pronounced hypothesis about loss of shape memory in alloy B with increasing quenching temperature as a function of volume fraction of thermoelastic and non-thermoelastic martensite.

Similar features in observed structures of decomposed samples for stabilised and nonthermoelastic martensite was found.

\section{Acknowledgements}

This work was carried out as part of research project 1/4137/07 supported by the Scientific Grant Agency of Ministry of Education of the Slovak Republic and the Slovak Academy of Sciences.

\section{References}

1. M. Vojtko, S. Longauer and M. Krkoška, SEMDOK 2003 (Žilina, 21.- 22. january 2003) 167-172.

2. S. Longauer, P. Makroczy, G. Janák and M. Longauerová, Material Science and Engineering A273275 (1999) 415-419

3. S. Longauer, M. Vojtko, G. Janák and M. Longauerová, J. Phys. IV France 112 (2003) 523-527. 